\title{
Backward Design of Theoretical Unit of College Table Tennis Live Broadcast Course during the Epidemic Period
}

\author{
Zhifei Wang1, Bin Wang1*, Peipei Song² \\ ${ }^{1}$ School of Physical Education and Health Sciences, Zhejiang Normal University, Jinhua, China \\ ${ }^{2}$ College of Liberal Arts, Xian Technology University, Xi'an, China \\ Email: wzfwangzhifei@outlook.com, *wangbin@zjnu.cn, 2268514916@qq.com
}

How to cite this paper: Wang, Z.F., Wang, B. and Song, P.P. (2020) Backward Design of Theoretical Unit of College Table Tennis Live Broadcast Course during the Epidemic Period. Open Access Library Journal, 7: e6697. https://doi.org/10.4236/oalib.1106697

Received: August 8, 2020

Accepted: September 7, 2020

Published: September 10, 2020

Copyright $\odot 2020$ by author(s) and Open Access Library Inc.

This work is licensed under the Creative Commons Attribution International License (CC BY 4.0).

http://creativecommons.org/licenses/by/4.0/

\begin{abstract}
Based on the theory of backward design, this paper uses the method of literature and logical analysis to carry out the backward design of table tennis theory unit live broadcast course. The research shows that: the live broadcast course adopted by backward design can enable students to face the epidemic, master the knowledge of table tennis batting elements, cultivate correct behavior habits of daily epidemic prevention and home exercise, improve the students' physical decline due to lack of exercise and the frequent occurrence of fear and anxiety caused by long-term stay at home; secondly, we should follow the thinking path of "end as the beginning", so as to make teaching more specific and targeted, and improve the consistency of objectives, evaluation and teaching. Third, the basic problems and performance tasks make teaching attractive and effective, which can solve the problems of students' low interest in learning and lack of motivation during the epidemic period. In short, the research can not only effectively complete the teaching task, improve the students' interest and enthusiasm in learning, but also improve the cognitive level and behavior ability of students in the prevention and control of epidemic and fitness exercise, which provides reference for the development of epidemic physical education curriculum and the enrichment of college physical education teaching design.
\end{abstract}

\section{Subject Areas}

Physical Education

\section{Keywords}

Backward Design, Live Broadcast Lesson, COVID-19, Table Tennis Theory 


\section{Introduction}

Under the severe situation of the rampant COVID-19 epidemic, people all over the country are actively implementing the epidemic prevention and control work at home. Students are faced with the dual task of epidemic prevention and course learning. Colleges and universities all over the country have started online courses in the form of "online courses", and various disciplines are facing fundamental changes in the teaching environment and teaching form. On February 12, the Ministry of Education issued a notice, clearly requiring "suspension of classes without suspension", adhering to the combination of national curriculum learning and prevention and control knowledge learning, focusing on strengthening patriotism education, life education and mental health education, and encouraging students to exercise [1]. In this context, due to the wide audience, flexibility of time and space, the online live sports courses of colleges and universities should actively practice the "perfect online teaching mode and improve the quality of students' physical education at home" during the epidemic prevention and control period. Develop epidemic sports courses and implement long-term epidemic sports education mechanism [2]. While paying attention to students' studies, online physical education courses can help students popularize epidemic prevention knowledge and ensure their physical and mental health in the epidemic prevention period.

At present, the research results of sports online education show that: the domestic online course teaching design has some deficiencies, such as too general and abstract learning objectives, lack of academic evaluation and testing level, and the light weight of learners' interaction [3]; the online course construction in sports colleges and universities lags behind; and the unit work and interaction link in the course operation are weak [4]. Therefore, under the new situation, the physical education discipline is in urgent need of a teaching design method that can highlight the value of the discipline and ensure the effect of online learning. The theory backward design is based on Understanding by Design co-authored by Grant Wiggins and Jay MC Tighe in 1998, which has been widely used in the teaching of foreign universities, middle schools and primary schools, spanning different grades and disciplines. Many studies have also shown the value and efficacy of the theory in the teaching field of various disciplines, but the theoretical and practical research in sports discipline is very few.

By sports live online course, based on the theoretical model of "backward by design", select the table tennis to win five elements, epidemic prevention and control, and promote physical and mental health of principle and method for the unit content of table tennis live the backward by design construction of courses, aims to enrich the teaching of backward design theory research, improve the college students during the epidemic prevention and control of will be coronavirus pneumonia, level of fitness exercise and the understanding of the factors of table tennis ball, improve students' anxiety, fear and other negative psychological feelings and lack of physical activity, improve students' confidence, to over- 
come the outbreak ready for school.

\section{Physical and Mental Status and Characteristics of College Students during the Epidemic}

In the Spring Festival of 2020, the emergence of COVID-19 disrupted people's normal life order. Studies have shown that during the epidemic prevention and control period, college students' excessive leisure at home was prominent, and $38.5 \%$ of students' physical activity decreased or did not exercise, and their physical condition was poor [5]. Nearly half of college students show obvious anxiety, and some even have serious anxiety [6]. The epidemic has led to an increase in negative emotions among college students, which fluctuate greatly, mainly in the following aspects: 1) fear caused by physical health; 2) tiredness caused by online home learning; 3 ) anxiety and loss caused by employment and college entrance pressure [7].

According to the existing research results, the COVID-19 epidemic has had a great impact on the daily life and study of college students in China. The main performance is the physical decline, anxiety and other negative emotions frequent birth of two urgent problems to be solved. Faced with this situation, the school must take its due responsibility. In addition, studies have pointed out that there is a significant correlation between college students' cognitive level of COVID-19 and their physical and mental health [8]. Therefore, by taking school physical education and health curriculum as a tool and integrating knowledge content of epidemic prevention and control, mental health adjustment and physical exercise into the online sports live broadcast curriculum, effective interventions are targeted to the above problems.

\section{Basic Theory of Live Online Courses}

Online live streaming course is one of the forms of online education. As a product of the Internet era, it emphasizes the combination of modern educational technology advantages and scientific educational concepts and methods, and advocates that one can learn anytime and anywhere. The American Online Learning Association defines online learning as: "Online learning refers to the education delivered mainly through the Internet by teaching activities and teaching contents, including web-based resources, media, tools, interactive activities, courses, teaching methods, etc." [9]. The live course in this study refers to the sum of the teaching content and teaching activities of a certain discipline under the online teaching form of simultaneous two-way communication via voice, video and other media.

Compared with the conventional offline teaching mode, the features of the online live course are as follows: 1) the space restriction is broken, and teachers and students are free to choose the location of the online class, which has mentioned the learning conditions for the special situation that the school cannot be opened due to the epidemic prevention and control; 2) compared with recorded 
and broadcast classes, it has the characteristics of timeliness and synchronization of information transmission, and can realize two-way communication just like real classes and give students timely feedback; 3) the video playback system allows students to review the contents of the class at any time, which is convenient for students to review.

\section{Theory of Backward by Design}

Backward by design is a teaching design mode based on the pre-set learning results according to the needs of students. Its connotation is that before designing teaching activities, teachers should first consider what the students want to achieve, that is, the expected teaching results, and then design the evaluation evidence to prove whether the teaching objectives are achieved or not, so as to make the learning objectives specific, and finally design specific teaching activities and implementation methods according to the teaching objectives [10]. The reason why the author calls it "reverse" is that traditional teaching design always considers what to teach and how to teach first, and usually starts from the analysis of teaching materials and learning situation, while backward design starts from the end (the expected learning goal) and backward teaching activities [11].

Backward design is divided into three stages. The first stage is to determine the expected learning results, which requires designers to consider what students should know, understand and do before designing teaching activities and contents [12]. The expected results of the first stage not only determine the nature of evaluation evidence in stage 2, but also provide guidance for teaching activities in stage 3. The second stage is the design evaluation evidence. In this stage, the designer is required to consider how to know whether the students have achieved the expected results and what evidence can be proved? And make the evaluation embedded in the teaching process and become a driving tool for teaching. The third stage is the design of teaching activities, which requires the designer to choose the suitable materials and resources according to the goal of the first stage? And how to carry out teaching? The backward design emphasizes taking the target as the starting point and the destination. In the research of the physical education discipline, most of the research is carried out from the theoretical level, which is of positive significance for clarifying the objective of the physical education discipline, implementing the core quality of physical education, and improving students' understanding of sports [13].

\section{Teaching Content of Theory Unit of Table Tennis Live Broadcast Course}

\subsection{Five Elements of Winning Table Tennis}

With the continuous reform of table tennis rules and equipment by the International Table Tennis Federation, table tennis players' technical and tactical styles are also changing. At the same time, table tennis players are required to have more comprehensive skills. However, the winning conditions are inseparable 
from the five winning elements of table tennis: arc, rotation, speed, strength and landing point.

Arc refers to the flying track of table tennis after hitting, which is composed of curve curvature, arc direction and hitting distance. The learning contents of the arc elements of table tennis in this unit are: 1) the function of the arc; 2) the elements affecting the arc (angle, speed and rotation of the hand).

The thickness and hardness of the sponge, the elasticity of the bottom plate, the nature of the rubber, and the force of hitting directly affect the degree of rotation of the ball. The learning contents of this unit about the rotation elements of Table Tennis include: 1) the main causes of rotation; 2) the basic types and characteristics of table tennis rotation; 3 ) the role of rotation; 4) the methods of dealing with different rotations.

The characteristic of table tennis is "fast and changeable". The fast attacking style characterized by high speed has its place in any period. This unit is about the speed elements of table tennis: the principle of improving the ball speed, the function of improving the ball speed and the method of improving the ball speed.

Hitting power refers to the force exerted by the racket on the ball, which is mainly determined by the performance of the racket and the swing speed at the moment of hitting.

This unit is about the power elements of table tennis: increase the impact of hitting power and adjust the way of hitting power.

It is very important to improve the effect of hitting the ball and strengthen the tactics to use by enhancing the consciousness of the landing point and changing the landing point flexibly. In this unit, we will learn about the drop points of table tennis: The effect of the drop points and the method of controlling the drop points.

\subsection{Basic Knowledge of COVID-19 and Its Individual Prevention and Treatment}

Novel coronavirus is a virus not previously found in human beings. The learning content of this unit on improving the understanding of coronavirus includes: what is the condition of killing coronavirus, susceptible group of coronavirus, transmission path of coronavirus, latency of coronavirus, and clinical performance of infected person

The prevention principle of novel coronavirus is mainly to block or reduce the virus invasion. The personal prevention learning content about novel coronavirus includes the following: correct way to go out, the choice and use of masks, notes on diet, attention to personal hygiene and good physical exercise habits

\subsection{Principles and Methods for Promoting Physical and Mental Health}

Physical and mental health is the basis and prerequisite for people to contribute to society and enjoy life. The content of this unit mainly includes: The concept 
of physical health and mental health the standard of health (WHO makes 10 health standards).

Scientific and moderate physical exercise is of great benefit to improving the quality of life and learning efficiency of students during the epidemic prevention period. It can also improve human immunity and reduce the risk of infection with bacteria and viruses. Aiming at the physical deterioration of college students during epidemic prevention and control, the knowledge content of this unit about physical exercise at home includes: the progressive principle of physical exercise, the intermittent physical exercise, the practice of table tennis at home and the sidesaddle.

Maintaining a positive and healthy mind is also the key to overcoming the epidemic. In view of the college students' anxiety, tension and other negative stress emotions during the epidemic prevention and control period, the knowledge content of this unit on mental health includes: the pertinence principle of psychological adjustment, the precautionary principle and the relaxation training method of self-psychological adjustment.

\section{Backward by Design of Theoretical Unit of Table Tennis Live Broadcast Course}

\subsection{Stage 1 of Backward Design: To Determine the Expected Learning Results}

\subsubsection{Expected Learning Results of the Five Elements of Winning Table Tennis}

Teaching objectives: 1) Master the five elements of table tennis to win the role of the generation and coping methods. 2) Through learning the five elements of table tennis to win, improve the knowledge and understanding of table tennis, improve the ability of appreciation of table tennis.

Students will be able to understand: 1) To win the table tennis competition, not only to improve the quality of the five elements of table tennis, but also according to the opponent's characteristics and the actual situation to seize the opportunity to choose a variety of coping methods. 2) In contrast to the five elements of the fast style play mainly have fast speed, low arc, weak rotation, the five elements of the loop style play is slightly slow speed, high arc, strong rotation, strong force.

Basic questions: 1) What are the characteristics of the velocity, arc, landing point, force and rotation of a high-quality ball? 2) What are the characteristics of the ball in table tennis that you are most likely to lose points? So how do we deal with that?

Students will know: 1) The five elements to improve the quality of the ball are: create a moderate arc, improve the speed of the fast break, increase the power of the ball, master the changing rotation law, control the return of the ball. 2) Table tennis rotation, speed, force, drop point, arc and the way to change. In the face of different rotation, speed, force, landing point, arc of the response measures.

Students will be able to: 1) be able to analyze and judge the technical characte- 
ristics of table tennis players according to the five factors, and enjoy the game; 2) can combine their own table tennis technical characteristics, analysis of their own table tennis to win the advantages and disadvantages of the five elements.

\subsubsection{Expected Learning Results of the Basic Principles and Methods to Promote the Healthy Development of Body and Mind}

Teaching objectives: Students will master the progressive principle, targeted principle and preventive principle of promoting physical and mental health, learn the ways and methods of physical exercise and mental health adjustment at home, and solve the physical decline and negative mental health problems of students during the epidemic prevention and control period.

Students will be able to understand: A healthy life not only needs the right amount of exercise and the right way of physical exercise, but also needs a positive and healthy mind. Individual due to age, physique and other physical conditions and the environment is different, everyone suitable for the psychological adjustment and physical exercise is also different.

Basic questions: Do you have a healthy lifestyle? What is healthy exercise for one person is not healthy exercise for another? What effect does negative emotion have on our body or daily life?

Students will know: 1) the concept and standard of health. 2) The progressive principle of physical exercise and the use of intermittent physical exercise method. 3) The pertinence principle of mental adjustment, the precautionary principle and the relaxation training method of mental adjustment the practice of table tennis at home with parallel step and sideslip step.

Students will be able to do: 1) Realize the importance of physical health and physical exercise, have good exercise habits. 2) Table tennis courses should be used for proper physical exercise during the epidemic. 3) Be able to adjust negative emotions through relaxation training method.

\subsubsection{Basic Knowledge of COVID-19 and Expected Learning Results of Individual Prevention and Treatment}

Teaching objectives: Students will master the basic knowledge of novel coronavirus and learn personal preventive measures to enhance the cognition of virus from novel coronavirus.

Students will be able to understand: novel coronavirus can be prevented by acting on its own. The prevention principle is to block or reduce the virus invasion.

Basic question: what do you know about novel coronavirus? How to avoid novel coronavirus infection?

Students will know the following knowledge: what is the condition of a novel coronavirus, the transmission path of a novel coronavirus, preventive measures, etc.

Students will be able to: form the correct daily anti-epidemic measures behavior. 


\subsection{Stage 2 of Backward Design: Design Evaluation Evidence}

\subsubsection{Evaluation Evidence of the Five Elements of Winning Table Tennis}

Performance task: Record a video. As a table tennis coach, your team members will have a match with a fast-attacking player. The teacher will send a video of the opponent's actual combat to students.

Case study: Watch a video of table tennis players from eastern and Western countries, and analyze the differences between the technical styles of table tennis players from representative western countries and those from eastern countries, as well as their advantages and disadvantages from five factors.

Declarative task: Explain the concepts and variation methods of table tennis rotation, speed, power, drop point and arc with my own understanding.

Student's statement: Analyze the rotation, speed, power, drop point and arc of his table tennis technique, and find out his shortcomings.

\subsubsection{Evidence for the Assessment of Basic Principles and Methods for the Promotion of Healthy Physical and Mental Development}

Performance task 1: "Health instructor"-based on the table tennis exercise method learned in this unit, combined with the progressive principle of physical exercise and personal situation, make a one-month home-based exercise plan by using the intermittent physical exercise method.

Case study: Analyze a physical activity program and discuss whether the progressive principle of physical activity can be followed and what can be improved.

Declarative task: Explain the knowledge content of this unit about physical and mental health with your own understanding.

\subsubsection{Basic Knowledge of COVID-19 and Assessment Evidence for Individual Prevention and Treatment}

Performance task: Record a video on novel coronavirus and epidemic prevention for family members as a teacher.

Self-assessment: Submit a report to reflect on your daily life based on the COVID-19 prevention measures you have learned and whether you have adopted the correct prevention behaviors.

Declarative task: Tell the story of this unit about novel coronavirus from your own understanding.

\subsection{Stage 3 of Backward Design: Design Teaching Activity Plan}

\subsubsection{Teaching Activity Plan of the First Class}

Content 1, the five elements of winning table tennis: 1) With the introduction of basic problems, to focus students' attention on the subject of the course and arouse students' thinking. 2) After thinking or discussing the basic problems freely, the teacher introduces the performance tasks of the five elements of table tennis curriculum. 3) The concepts, functions, principles and types of the five elements of table tennis arc, rotation, speed, force and landing point are respectively taught. 4) Teacher summarizes this part of knowledge.

Content 2, the basic principles and methods of promoting the healthy devel- 
opment of body and mind: 1) With an introduction question (do you have a healthy lifestyle?) Cut in and guide the students to think about what a healthy lifestyle is. 2) After thinking freely or discussing the basic problems, discuss the final expressive task of the unit. 3) The teacher tells the concept and standard of health, and the students discuss which behaviors are harmful to health according to the standard of health and daily experience (the students type the discussion results in the chat column). 4) Watch videos and cases about bad behaviors and their consequences, sort out what is a healthy behavior, and increase students' understanding of health. 5) The teacher summarizes this part of the content knowledge points.

Content 3, basic knowledge of COVID-19 and its personal prevention and cure: 1) With a basic question (think what do you know about novel Coronavirus?) Introduce, bring the student's attention to the topic of today's lecture and recall the cognition of novel Coronavirus. 2) After thinking freely or discussing basic questions, the teacher introduces the expressive tasks of COVID-19 curriculum content. 3) The student typed in the chat box what he knew about novel coronavirus. 4) Teacher will sort out the information in the chat bar, tell and supplement the study on Novel Coronavirus in this unit. 5) Teacher summarizes the knowledge of this part.

\subsubsection{Teaching Activity Plan for the Second Period}

Content 1, the five elements of winning table tennis: 1) Students should answer in groups or check the knowledge points learned in the last class and carry out the declarative task (explain the knowledge points with their own understanding). 2) Watch the video of table tennis match. The teacher analyzes the characteristics of winning through the five elements to improve students' understanding of the five elements. 3) To a basic problem into (table tennis in their own most easy to lose points to the ball has what characteristics? So how do we deal with it? 4) The variation methods and countermeasures of the five elements of table tennis arc, rotation, speed, force and landing point are respectively introduced. 5) The teacher summarizes this part of the content knowledge points.

Content 2, promote the basic principles and methods of physical and mental health development: 1) Discuss the basic problem, for one person healthy exercise, why for another person is not healthy? Get the students to think about what is required for good physical exercise. 2) Teaching the principle of progressive physical exercise and intermittent exercise. 3) Case analysis. Analyze a case of physical exercise plan, discuss whether to follow the progressive principle of physical exercise, what kinds of exercise methods are adopted in the video, and what aspects can be improved. 4) The teacher shows the table tennis step movement exercise technique through the video, the student imitates the exercise, the teacher points out the movement through the video. 5) The teacher summarizes this part of the content knowledge points.

Content 3, basic knowledge of COVID-19 and its personal prevention and control: 1) Students should answer in groups or check the knowledge points of 
the last class by sampling, and perform presentation tasks (explain the knowledge points with their own understanding). 2) Students discussed what changes have taken place in people's behaviors since the outbreak of the epidemic? What's true and what's not true? 3) Teachers according to the information in the chat bar to sort out, about and supplement the correct personal behavior prevention measures of learning content. 4) The teacher summarizes the knowledge points of this part of the unit. 5) Arrange after-class performance tasks and self-evaluation tasks. Self-assessment assignments are due at the end of the semester.

\subsubsection{Teaching Activity Plan for the Third Period}

Content 1, table tennis to win five elements: 1) Arrangement of case analysis tasks, watched a video game of national table tennis players in the east and west, team discussion, from the aspects of five elements analysis of the typical western table tennis athletes and the difference between the technical style of Oriental athletes and their advantages and disadvantages. 2) The teacher analyzed the technical style of table tennis players from the representative Eastern and Western countries from five aspects. 3) Students should complete the self-evaluation task according to the teacher's analysis method, analyze the rotation, speed, strength, landing point and arc of their own table tennis technical style, and find out their own technical style positioning. 4) The teacher summarizes the knowledge points of this part of the unit. 5) Assign performance tasks at the end of table tennis unit content.

Content 2, the basic principles and methods to promote the healthy development of body and mind: 1) Discuss the basic problems (what impact does negative emotion have on our body or daily life?) Stimulate students' interest and motivation in the course content. 2) Students speak, talk about their own negative emotions will use what methods to deal with. 3) Teaching the pertinence principle and prevention principle of mental health adjustment. 4) Teach the relaxation training method of mental health adjustment, and take the students to practice the method. 5) After the teacher tells the story, the students answer in groups or make spot checks, ask questions about the knowledge points learned in this class, and perform declarative tasks (explain the knowledge points in their own understanding). 6) Teachers summarize the knowledge points of this part of the unit and assign performance tasks.

\section{Performance Evaluation of Theoretical Unit of Table Tennis Live Broadcast Course}

With the development of education reform in China, evaluation has become the key point of reform. Diversified evaluation methods play the roles of diagnosis, feedback, reflection, summary and promotion in teaching, and their fundamental purpose is to improve the teaching effect. The performance of students in this unit starts from the performance tasks, classroom performance and student attendance. The average score of all performance tasks in this unit is taken as the 
basic score of the unit, and the basic score is added or subtracted from the class performance and student attendance.

\section{Conclusions}

During the epidemic prevention and control period, online physical education courses are an effective way to ensure students acquire physical education and health knowledge and to actively fulfill the value of school physical education in epidemic prevention and control. At this stage, it is the value responsibility of school physical education curriculum to popularize knowledge of epidemic prevention and control, home fitness and exercise, and alleviate negative psychological emotions according to students' needs. The backward design of sports live broadcast course with these contents can effectively improve students' cognitive level of new coronavirus, home physical exercise and mental health principles, table tennis batting elements knowledge, meanwhile, it can help students establish correct daily epidemic prevention behaviors, form positive daily exercise behaviors and habits, and master effective ways to relieve anxiety, fear and other negative psychological emotions.

The backward design follows the thinking path of "starting from the end". Firstly, according to the needs of students during the epidemic prevention period, such as popularizing the knowledge of epidemic prevention and control, strengthening the physical fitness at home and alleviating the negative psychological emotions, the backward design aims to make the teaching objectives and directions more clear, cultivate the knowledge and skills required by students and improve their cognitive level. Secondly, through the evaluation first, the teaching evaluation is integrated into the teaching process, so that the teachers can adjust the teaching process according to the feedback of the evaluation in the teaching process, and increase the interaction between teachers and students through the activities such as questionnaire and case analysis, which not only increases the students' desire to participate, but also makes the teaching objectives more visual and specific. Teaching activities and evaluation are closely related to the objectives and increase the consistency of objectives, evaluation and teaching. Finally, basic questions with the nature of inquiry can trigger students' active thinking and enhance their desire to learn. Challenging performance tasks can be both attractive and effective, trigger a variety of practical activities, increase students' curiosity and motivation, and help solve the problem of students' lack of interest and motivation in learning during the epidemic period.

As a means to promote students to achieve their goals, teaching activities are open and flexible. After clarifying the expected results and evaluating evidence, teachers should not only rely on the most familiar or favorite methods to choose teaching methods, but also think about which activities can enable students to acquire the required knowledge and skills. Therefore, backward design not only focuses on students as the main body, but also emphasizes the importance of teachers' teaching knowledge and skills, subject knowledge and skills, and their 
own experience. In a word, the reverse teaching design of the theoretical unit of table tennis direct broadcast course in colleges and universities during the war "epidemic" period can not only effectively completes the teaching task, improves the learning interest and enthusiasm, but also improves the cognitive level and behavior ability of students in the prevention and control of epidemic situation and fitness exercise, which can provide reference for better fighting against the epidemic situation, developing epidemic physical education curriculum and enriching college physical education teaching design.

\section{Conflicts of Interest}

The authors declare no conflicts of interest regarding the publication of this paper.

\section{References}

[1] Guo, Z. (2020) Construction of the Cooperative Mental Health Education System for Primary and Secondary Schools in "Emergency Period". Liaoning Education, No. 8, 5-11.

[2] Dong, P., Cheng, C. and Zhao, F. (2020) COVID-19 Outbreak of School Sports Value, Mission and Bear. Sports Science Research, No. 2, 59-64.

https://doi.org/10.15877/j.cnki.nsic.20200318.001

[3] Fan, H. (2017) Analysis on the Effectiveness of Online Course Teaching Design-Based on the Learning Enlightenment of "Applying the Quality Matters Rubric" Online Course. Teaching Research, 40, 50-53.

[4] Wang, H., Zhao, H. and Yu, J. (2019) Current Situation Analysis and Development Countermeasures of Mooc Physical Education Curriculum Construction in Chinese Universities. Journal of Wuhan Institute of Physical Education, 53, 69-75.

[5] Research Group of New Learning and Engineering Innovation Center of Southwest University and Sun, C. (2020) Study on the Impact of COVID-19 on Young College Students-Based on an Empirical Survey of 19,850 College Students in 45 Universities. China Youth Research, No. 4, 43-48.

[6] Wang, Y. (2020) Study on Anxiety Level of College Students and Its Influencing Factors during Epidemic Prevention And Control. Journal of Teacher Education, 7, 76-83.

[7] Zhao, B., Cai, T. and Zhang, Z. (2020) Presentation and Adjustment of College Students' Emotional State under COVID-19 Epidemic-From the Perspective of Self-Care. China Youth Research, No. 4, 49-54.

[8] Li, Y. and Chen, K. (2020) Current Situation of College Students' Cognition of COVID-19 Epidemic and Its Relationship with Physical and Mental Health. Journal of Henan University (Social Science Edition), 60, 20-25.

[9] Gan, Y. (2017) Research on Blended College English Teaching Based on Online Live Class. Educational Academic Monthly, 11, 79-87.

[10] Wiggins, G. and McTighe, J. (2017) Teaching Design for Understanding. East China Normal University Press, Shanghai.

[11] Li, R. (2008) Instructional Design Aiming at Discipline Core Quality. Curriculum Textbook Teaching Method, 38, 35-40.

[12] Wiggins, G. and McTighe, J. (2005) Understanding by Design: Expanded Second 
Edition. Pearson Schweiz AG, Switzerland.

[13] Wang, Z., Wang, B., Gong, L. and Wang, G. (2020) The Connotation of Backward Design and Its Research Status in Physical Education. Journal of Research in Vocational Education, 2, 68-70. 